Cite this paper as: Ruiz-Teran AM, Aparicio AC, 2007, Parameters governing the response of underdeck cable-stayed bridges, Canadian Journal of Civil Engineering, Vol:34, ISSN:0315-1468, Pages:1016-1024 [doi: 10.1139/L07-016]

\title{
Parameters governing the response of under-deck cable-stayed bridges.
}

\author{
A.M. Ruiz-Teran ${ }^{\mathrm{a},{ }^{*}}$, A.C. Aparicio ${ }^{\mathrm{b}}$ \\ ${ }^{a}$ Assistant Professor. Department of Civil Engineering and Building. University of Castilla- \\ La Mancha. \\ Academic Visitor at Imperial College London, UK \\ Av. Camilo José Cela s/n 13071. Ciudad Real. Spain \\ ${ }^{\mathrm{b}}$ Professor. Department of Construction Engineering. Technical University of Catalonia. \\ C. Jordi Girona 1-3. 08034. Barcelona. Spain.
}

\section{Word count:}

Title and address....

Abstract and key words

Sections 1-6

Acknowledgments .

References

List of symbols 266

7 Figures $(7 \times 250)$ 1750

Total 6982

Tel: +34926295300 (ext. 3277) Fax: +34926295391 E-mail: AnaMaria.Ruiz@uclm.es or aruiter@ciccp.es 
Cite this paper as: Ruiz-Teran AM, Aparicio AC, 2007, Parameters governing the response of underdeck cable-stayed bridges, Canadian Journal of Civil Engineering, Vol:34, ISSN:0315-1468, Pages:1016-1024 [doi: 10.1139/L07-016]

Abstract: In the past quarter century a number of bridges have been built that do not fit into the conventional types of cable-stayed bridges. These are under-deck cable-stayed bridges and combined cable-stayed bridges. In this paper we define the first of these two types and set out its mechanisms of response. We then establish and analyse the parameters that determine the permanent response and the response to live load of these bridges. Lastly, we draw conclusions relating to their behaviour and we define design criteria for them with the aim of making cable-staying systems highly efficient and allowing the design of much lighter and slimmer structures.

Keywords: unconventional cable-stayed bridges, under-deck cable-stayed bridge, combined cable-stayed bridge 
Cite this paper as: Ruiz-Teran AM, Aparicio AC, 2007, Parameters governing the response of underdeck cable-stayed bridges, Canadian Journal of Civil Engineering, Vol:34, ISSN:0315-1468, Pages:1016-1024 [doi: 10.1139/L07-016]

\section{Introduction}

In the past quarter century a number of bridges have been built that do not fit into the conventional types of cable-stayed bridges. We can divide them clearly into two structural types: under-deck cable-stayed bridges and combined cable-stayed bridges (Ruiz-Teran and Aparicio 2006). The work set out in this paper focuses on the first of those two types and forms part of the doctoral thesis (Ruiz-Teran 2005) written by the first author under the supervision of the second author.

\section{Under-Deck Cable-Stayed Bridges}

In under-deck cable-stayed bridges (UCSB), the stay cables, that have a polygonal layout under the intrados of the deck, are self-anchored in the deck in the support sections over piers or abutments, and they are deflected by struts which, under compression, introduce the cable upward deviation forces into the deck. Some examples of this type of bridges are: the Weitingen viaduct (Leonhardt 1982), designed by Fritz Leonhardt and built in 1978; the Truc de la Fare overpass (Virlogeux et al. 1994), designed by Michael Virlogeux and built in 1993 (Figure 1); and the Osormort viaduct (Lluch et al. 2001), designed by Javier Manterola and built in 1995 (Figure 2).

In these bridges, as in classic cable-stayed bridges, the stay cables are prestressed. After the prestressing of the stay cables, the upward deviation forces introduced into the deck by means of the struts compensate the permanent loads: dead load (self-weight of structural elements) and superimposed dead load (self-weight of non structural elements). Therefore, in permanent state, the flexural response (bending of the deck) is greatly reduced whereas the axial response (tension of the stay cables, and compression of the struts and the deck) is increased. After prestressing, the bending of the deck due to permanent actions (dead load, superimposed dead load and prestressing) is similar to that found in a continuous beam with supports at the points 
Cite this paper as: Ruiz-Teran AM, Aparicio AC, 2007, Parameters governing the response of underdeck cable-stayed bridges, Canadian Journal of Civil Engineering, Vol:34, ISSN:0315-1468, Pages:1016-1024 [doi: 10.1139/L07-016]

where the deck lays over the struts. In addition, because the under-deck cable-staying system is efficient in response to live load, the bending of the deck due to the action of the live load is also reduced in comparison with bridges without stay cables, since a portion of the live load is resisted through the tension of the stay cables and the compression of the struts and the deck. Consequently, these bridges have two mechanisms of response to vertical loads: (1) the axial response by means of tension of stay cables and compression of the struts and the deck; and (2) the flexural response of the deck. Figure 3 represents these two mechanisms of response in an under-deck cable-stayed bridge and with just one strut placed at midspan in the presence of a uniform vertical load.

\section{A review of previous studies.}

The studies to date on the subject of unconventional cable-stayed bridges have been made in six places: at the IBK of the ETH in Switzerland (Menn and Gauvreau 1990; Fürst and Marti 1999; Laffanchi and Marti 1999); at the ILEK of the University of Stuttgart in Germany (Ploch 2004; Lemaitre and Kobler 2005); at the Swiss Federal Institute of Technology of Lausanne, in Switzerland (Muttoni 2002); at Nihon University in Japan (Umezu et al. 1998; Saitoh 1998); at Saitama University in Japan (Aravinthan et al. 2005), and lastly, the work developed by the authors in Spain (Ruiz-Teran 2005).

Only a very few studies have been made. Some of them consist of experimental tests performed in connection with increasing the eccentricity of the active reinforcements in beams with external prestressing (Menn and Gauvreau 1990; Umezu et al. 1998; Aravinthan et al. 2005). Others deal with these structures as new structural types with their own identity (Laffanchi and Marti 1999; Lematire and Kobler 2005; Muttoni 2002). Only two of the works attempt to identify the parameters involved in the structural response of these bridges. Muttoni (2002) identifies the influence of the morphology of the structure and the number of 
Cite this paper as: Ruiz-Teran AM, Aparicio AC, 2007, Parameters governing the response of underdeck cable-stayed bridges, Canadian Journal of Civil Engineering, Vol:34, ISSN:0315-1468, Pages:1016-1024 [doi: 10.1139/L07-016]

struts in the reduction of the bending moments in the deck due to live load in comparison with a bridge without stay cables. Lemaitre and Kobler (2005) show that, in the specific case of an under-deck cable-stayed bridge with three struts with a particular configuration and some specific support conditions that do not allow the axial shortening of the deck, the axial response of the structure is determined by a function that depends exclusively on two parameters, as shown in the following equation:

$$
f\left(\frac{E \cdot I}{E_{S C} \cdot A_{S C} \cdot L^{2}} \quad, \quad \frac{L_{S}}{L}\right)
$$

where $E \cdot I$ is the flexural rigidity of the deck, $E_{S C} \cdot A_{S C}$ is the tensile rigidity of the stay cables, $L$ is the span of the bridge and $L_{S}$ is the length of the strut placed at midspan.

The work performed by the authors of this paper has obtained the parameters that govern the response of under-deck cable-stayed bridges in general for any type of these structures.

\section{Parameters governing response}

\subsection{Under-deck cable-stayed bridge with one strut}

Let us look at the response of an under-deck cable-stayed bridge, with a span $L$, where the strut placed at midspan has a length $L_{S}$ (in other words, the under-deck stay cables form an angle $\alpha$ with the deck). The deck has a deformation modulus of $E$, a cross-sectional area $A$ and a moment of inertia $I$. The stay cables have an elastic modulus $E_{S C}$ and an area $A_{S C}$.

\subsubsection{Permanent state response prior to time-dependent effects}

In a cable-stayed bridge, the stay cables are prestressed and tensed up to a tension $\sigma_{0}$. The tensing of the stay cables compensates a portion $(\rho)$ of the dead load $\left(g_{1}\right)$ and the superimposed dead load $\left(g_{2}\right)$. By compensating $100 \%(\rho=1)$, we can reduce the design span 
Cite this paper as: Ruiz-Teran AM, Aparicio AC, 2007, Parameters governing the response of underdeck cable-stayed bridges, Canadian Journal of Civil Engineering, Vol:34, ISSN:0315-1468, Pages:1016-1024 [doi: 10.1139/L07-016]

length by half under permanent actions. We name this effect 'span subdivision'. Consequently, the bending moments in the deck are reduced to one quarter of that in an identical deck without under-deck stay cables.

The cable upward deviation force $\left(\mathrm{R}_{0}\right)$ introduced by the struts into the deck is given by the equations set out below. These equations are for the permanent state, prior to any redistribution of forces due to time-dependent effects.

In a single-span bridge:

[2] $\quad R_{0}=\rho \cdot \frac{5}{8} \cdot L \cdot\left(g_{1}+g_{2}\right)=2 \cdot \sigma_{0} \cdot A_{S C} \cdot \sin (\alpha)$

And in a continuous bridge:

$$
R_{0}=\rho \cdot \frac{1}{2} \cdot L \cdot\left(g_{1}+g_{2}\right)=2 \cdot \sigma_{0} \cdot A_{S C} \cdot \sin (\alpha)
$$

\subsubsection{Response to live load}

The response to live load for two under-deck cable-stayed bridges with a single strut placed at midspan has been obtained. One of the bridges is simply supported and the other has fixed supports. Three different types of loading have been considered: a uniform live load q, a point load Q applied at midspan, and two bending moments applied at the supports. In all cases, the response of the structure (in forces and deflections) has been obtained after making an analytical exposition, resolving the structure using the flexibility method, and grouping the different terms appropriately. We noted that in all the cases studied the response of the structure depends on a single dimensionless parameter $\chi$. This parameter, which governs the response of the structure in terms of both forces and deflections, is independent of the type of applied load and the support conditions, and has the following form: 
Cite this paper as: Ruiz-Teran AM, Aparicio AC, 2007, Parameters governing the response of underdeck cable-stayed bridges, Canadian Journal of Civil Engineering, Vol:34, ISSN:0315-1468, Pages:1016-1024 [doi: 10.1139/L07-016]

$$
\chi=\chi_{I}+\frac{\chi_{I}}{\chi_{A}}
$$

where $\chi_{\mathrm{I}}$ and $\chi_{\mathrm{A}}$ are given by the following equations:

$$
\chi_{I}=\frac{E \cdot I}{\sin ^{2}(\alpha) \cdot \cos (\alpha) \cdot E_{S C} \cdot A_{S C} \cdot L^{2}}
$$

$$
\chi_{A}=\frac{E \cdot A}{\cos ^{3}(\alpha) \cdot E_{S C} \cdot A_{S C}}
$$

If we substitute equations [5] and [6] in [4] we obtain:

$$
\chi=\chi_{I}+\frac{\chi_{I}}{\chi_{A}}=\frac{E \cdot I}{\sin ^{2}(\alpha) \cdot \cos (\alpha) \cdot E_{S C} \cdot A_{S C} \cdot L^{2}}+\frac{\cos ^{2}(\alpha) \cdot I}{\sin ^{2}(\alpha) \cdot A \cdot L^{2}}
$$

The first term $\chi_{\mathrm{I}}$ relates the flexural rigidity of the deck to the axial rigidity of the under-deck cable-staying system. The second term $\chi_{\mathrm{I}} / \chi_{\mathrm{A}}$ relates the square of the radius of gyration of the deck $(I / A)$ to the span squared; it is therefore the inverse of the square of the mechanical slenderness of the deck. Consequently, the term $\chi$ is a dimensionless coefficient that provides an idea of the relative rigidity of the deck in relation to the rigidity of the under-deck cablestaying system, and therefore we have named it "relative rigidity of the deck to the underdeck cable-staying system"

We have defined a second dimensionless parameter $\xi$, that we have named "efficiency of the cable-staying system under live load". We define this second parameter as the portion of the external isostatic bending moment due to live load (either $q L^{2} / 8$ or $Q L / 4$, as the case may be) that is resisted by the under-deck cable-staying system. The study showed that the efficiency of the cable-staying system $(\xi)$ depends on the relative rigidity $(\chi)$, the support conditions, 
Cite this paper as: Ruiz-Teran AM, Aparicio AC, 2007, Parameters governing the response of underdeck cable-stayed bridges, Canadian Journal of Civil Engineering, Vol:34, ISSN:0315-1468, Pages:1016-1024 [doi: 10.1139/L07-016]

and the type of load applied. Likewise, we noted that the response of the structure can be obtained on the basis of this second parameter. Figure 4 shows the equations that allow us to obtain the efficiency of the cable-staying system, as well as the internal forces and deflections at different points in the structure (bending moment at midspan section, bending moment over support sections, stress changes in the stay cables, deflection at midspan, and axial force in the deck) for the different loading cases and support conditions considered. We can draw many conclusions on the basis of this figure, the most important of which being the following:

- The efficiency of the cable-staying system $\xi$ will increase proportionally to the reduction in the relative stiffness $\chi$.

- If we fix the mechanical and geometric characteristics of an under-deck cable-stayed bridge, i.e. if we establish the value of the parameter $\chi$, we can study the influence of the supports conditions (pinned or fixed) on the efficiency of the cable-staying system. We see that the efficiency of the cable-staying system is greater in a simply supported scheme than in a fixed scheme. In other words, we can obtain the same efficiency for the cablestaying system with a relative stiffness $\chi$ in the simply supported scheme as with a relative stiffness $\chi / 4$ in the fixed scheme.

- In a continuous bridge, the maximum sagging bending moment at midspan is obtained by loading alternate spans. If we apply the principle of superimposition, the bending moment is equal to the sum of the moments obtained in a beam with a single span and with an identical under-deck cable-staying system, where half the load acts on a simply supported scheme (in which the under-deck cable-staying system is more efficient) and the other half acts on a fixed scheme (in which the under-deck cable-staying system is less efficient). Thus, the reduction of the sagging bending moment at midspan in a continuous 
Cite this paper as: Ruiz-Teran AM, Aparicio AC, 2007, Parameters governing the response of underdeck cable-stayed bridges, Canadian Journal of Civil Engineering, Vol:34, ISSN:0315-1468, Pages:1016-1024 [doi: 10.1139/L07-016]

bridge due to the cable-stayed system will be less than if the full load acts on a simply supported scheme. Consequently, the reduction of the sagging bending moment at midspan in a continuous bridge with an under-deck cable-staying system is less than in a bridge of the same characteristics with independent spans.

- In a continuous bridge, the maximum hogging bending moment in the support section over the pier is obtained approximately by applying the live load to the whole bridge. In fact, this gives a value that is lower than the actual value. The behaviour is quite similar to that of a fixed single span. In fact, the maximum negative bending moment in the continuous bridge is equal to that of the fixed span multiplied by a factor that depends exclusively on $\xi$. We already know that with the fixed scheme the under-deck cablestaying system is less efficient. Furthermore, when it comes to calculating the hogging moments in the support sections, the efficiency is reduced by a fact of $3 / 4$. Thus, underdeck cable-staying systems are highly inefficient at resisting hogging bending moments in the support sections over the piers.

- In any of the configurations considered, deflection at midspan is zero when the efficiency of the cable-staying system is at its maximum value. This circumstance arises when the relative rigidity $\chi$ is zero, or, equivalently, when the stay cables are infinitely stiff.

- Furthermore, in any of the configurations considered, when the efficiency of the cablestaying system is zero, i.e. when the relative stiffness $\chi$ has a value of infinity or, in other words, when the tensile rigidity of the cable-staying system is zero, the internal forces and deflections coincide with those of a beam without under-deck stay cables (either simply supported or fixed, as the case may be).

Let us now determine the stress changes in the stay cables due to live load in a simply 
Cite this paper as: Ruiz-Teran AM, Aparicio AC, 2007, Parameters governing the response of underdeck cable-stayed bridges, Canadian Journal of Civil Engineering, Vol:34, ISSN:0315-1468, Pages:1016-1024 [doi: 10.1139/L07-016]

supported under-deck cable-stayed bridge with a single span (or a bridge with multiple independent spans). The maximum tension in the stay cables occurs when the uniform live load $q$ acts on the whole deck and when the point load $Q$ acts at midspan. The minimum tension is the zero tension that occurs when no live load is acting. If we take the equations set out in Figure 4 that allow us to calculate the stress changes in the stay cables for these actions and we eliminate the area of the stay cables using equation [2], we find that the stress changes in the stay cables $(\Delta \sigma)$ due to live load $(q$ and $Q)$ in a single-span simply-supported bridge is given by the following equation:

$$
\Delta \sigma_{S C}=\frac{\sigma_{0}}{\rho \cdot\left(g_{1}+g_{2}\right)} \cdot\left(q+\frac{8}{5} \cdot \frac{Q}{L}\right) \cdot \frac{1}{1+12 \cdot \chi}
$$

Analogously, we can determine the variation in tension in the stay cables of a continuous bridge. To do so, we need to use the equations set out in Figure 4 and apply the principle of superimposition. Once again, we eliminate the area of the stay cables using equation [3]. Thus, the stress changes in the stay cables $(\Delta \sigma)$ due to live load ( $q$ and $Q$ ) in continuous bridges is given by the following equation:

$$
\Delta \sigma_{S C}=\frac{5}{4} \cdot \frac{\sigma_{0}}{\rho \cdot\left(g_{1}+g_{2}\right)} \cdot\left(q+\frac{8}{5} \cdot \frac{Q}{L} \cdot f_{Q}\right) \cdot \frac{1}{1+12 \cdot \chi}
$$

$$
f_{Q}=0.7003+\frac{0.2997}{1+24.8052 \cdot \chi}
$$

We note that the stress changes due to the load Q are effected by a function $f_{Q}$ that takes into account the fact that that load can only be applied to one point of the structure. This factor was obtained numerically and depends exclusively on the dimensionless coefficient $\chi$.

In order to reduce the flexural response of the deck, we wish to ensure that the under-deck 
Cite this paper as: Ruiz-Teran AM, Aparicio AC, 2007, Parameters governing the response of underdeck cable-stayed bridges, Canadian Journal of Civil Engineering, Vol:34, ISSN:0315-1468, Pages:1016-1024 [doi: 10.1139/L07-016]

cable-staying system is efficient under live load, but this obligates us to check the fatigue limit state of the stay cables caused by the action of the frequent live load. To perform this check, we directly apply equations [8] and [9].

\subsection{Under-deck cable-stayed bridge with multiple struts}

Let us consider an under-deck cable-stayed bridge with multiple struts ( $n$ struts). The span has a length $L$ and the strut placed at midspan has a length $L_{S}$ (or, equivalently, the length of the strut is $r \cdot L$ ). The deck has a modulus of deformation $E$, a cross-sectional area $A$ and a moment of inertia $I$. The stay cables, that assume a parabolic layout, have an elastic modulus $E_{S C}$ and a cross-sectional area $A_{S C}$.

\subsubsection{Permanent state response prior to time-dependent effects}

The tensing of the stay cables compensates a portion $(\rho)$ of the dead load $\left(g_{1}\right)$ and the superimposed dead load $\left(\mathrm{g}_{2}\right)$. In a system with $n$ struts, by compensating $100 \%(\rho=1)$, we will succeed in 'subdividing the span' under permanent actions (dead load, superimposed dead load and prestressing). Under permanent load, prior to time-dependent effects, the design span length is reduced to the separation between struts (s):

$$
\text { [11] } \quad s=\frac{L}{n+1}
$$

This means that the bending moments of the deck due to those actions will be reduced by a factor of $(s / L)^{2}$ in comparison with the moments in an identical deck without stay cables.

The prestressing tension of the stay cables is given by: 
Cite this paper as: Ruiz-Teran AM, Aparicio AC, 2007, Parameters governing the response of underdeck cable-stayed bridges, Canadian Journal of Civil Engineering, Vol:34, ISSN:0315-1468, Pages:1016-1024 [doi: 10.1139/L07-016]

$$
\rho \cdot\left(g_{1}+g_{2}\right)=\sigma_{0} \cdot A_{S C} \cdot \frac{8 \cdot r}{L}
$$

\subsubsection{Response to live load}

The response to live load of an under-deck cable-stayed bridge with multiple struts, in which the under-deck stay cables describe a parabolic layout, has been obtained. Two load states have been considered: (1) a uniform live load q and (2) point load Q applied at midspan. In both cases, the response of the structure (in internal forces and deflections) has been obtained. To that end, we took as unknown the deviation forces between the deck and the under-deck cable-staying system. Given that the cable-staying system has a parabolic layout, the deviation forces are uniform. The value of this unknown was obtained by minimising the deformation energy of the whole structure. Having determined the force of interaction between the deck and the cable-staying system, i.e. the cable deviation force, the response of the structure is determined. After grouping all the terms appropriately, we once again noted that the response of the structure (in internal forces and deflections) depends on just one dimensionless parameter $\chi$, and that this parameter is the sum of two terms as in equation [4]. In this case, $\chi_{\mathrm{I}}$ and $\chi_{\mathrm{A}}$ are given by the following equations:

$$
\chi_{I}=\frac{E \cdot I}{E_{S C} \cdot A_{S C} \cdot L^{2}} \cdot \frac{5}{32} \cdot\left(\frac{1}{r^{2}}+\frac{16}{3}\right)
$$

$$
\chi_{A}=\frac{E \cdot A}{E_{S C} \cdot A_{S C}} \cdot\left(1+\frac{16 \cdot r^{2}}{3}\right)
$$

Figure 5 shows the equations required in order to obtain the efficiency of the cable-staying system, as well as the internal forces and deflections at different points of the structure (bending moment in the midspan section, bending moment in the support section, stress 
Cite this paper as: Ruiz-Teran AM, Aparicio AC, 2007, Parameters governing the response of underdeck cable-stayed bridges, Canadian Journal of Civil Engineering, Vol:34, ISSN:0315-1468, Pages:1016-1024 [doi: 10.1139/L07-016]

changes in the stay cables, deflection at midspan, and axial force in the deck) for the two load cases considered. If we take the equations set out in this figure that allow us to calculate the stress changes in the stay cables for these actions, and we eliminate the area of the stay cables using equation [12], we find that the stress changes in the stay cables $(\Delta \sigma)$ due to live load $(q$ and $Q$ ) in a single-span bridge with multiple struts is given by the following equation:

$$
\Delta \sigma_{S C}=\frac{\sigma_{0}}{\rho \cdot\left(g_{1}+g_{2}\right)} \cdot\left(q+\frac{25}{16} \cdot \frac{Q}{L}\right) \cdot \frac{1}{1+12 \cdot \chi}
$$

This equation will be useful for checking the fatigue limit state in the stay cables.

\subsection{Under-deck cable-stayed bridge. The general case}

\subsubsection{Dimensionless parameter governing the behaviour. The general case}

In an under-deck cable-stayed bridge, the parameter $\chi$ depends on the geometric functions $\mathrm{g}_{\mathrm{I}}$ and $g_{A}$. Those two functions depend in turn on the ratio of the length of the midspan strut to the span $\left(L_{S} / L\right)$ and on the number of struts $n$.

$$
\chi=\chi_{I}+\frac{\chi_{I}}{\chi_{A}}=\frac{E \cdot I}{E_{S C} \cdot A_{S C} \cdot L^{2}} \cdot g_{I}\left(\frac{L_{S}}{L}, n\right)+\frac{I}{A \cdot L^{2}} \cdot g_{A}\left(\frac{L_{S}}{L}, n\right)
$$

For a single strut $(n=1)$ :

$$
g_{I}\left(\frac{L_{S}}{L}, 1\right)=\frac{1}{\sin ^{2}(\alpha) \cdot \cos (\alpha)}
$$

$$
g_{A}\left(\frac{L_{S}}{L}, 1\right)=\frac{\cos ^{2}(\alpha)}{\sin ^{2}(\alpha)}
$$

For multiple struts $(n=\infty)$ : 
Cite this paper as: Ruiz-Teran AM, Aparicio AC, 2007, Parameters governing the response of underdeck cable-stayed bridges, Canadian Journal of Civil Engineering, Vol:34, ISSN:0315-1468, Pages:1016-1024 [doi: 10.1139/L07-016]

$$
g_{I}\left(\frac{L_{S}}{L}, \infty\right)=\frac{5}{32}\left(\frac{1}{r^{2}}+\frac{16}{3}\right)=\frac{5}{32}\left(\frac{L^{2}}{L_{S}{ }^{2}}+\frac{16}{3}\right)
$$

$$
g_{A}\left(\frac{L_{S}}{L}, \infty\right)=\frac{5}{32} \cdot \frac{1}{r^{2}}=\frac{5}{32} \cdot \frac{L^{2}}{L_{S}{ }^{2}}
$$

In equation [1] we showed the parameters identified by Lemaitre and Kobler (2005) in determining the axial response of an under-deck cable-stayed bridge with three struts, with a given geometrical configuration. The scheme that they proposed was only valid when the lateral struts had a given length relative to the central struts. We can see that these parameters identified by Lemaitre and Kobler are merely a specific instance of the case presented in equation [16] when the term $\chi_{\mathrm{I}} / \chi_{\mathrm{A}}$ is disregarded or, in other words, when the axial shortening of the deck is disregarded. We see, then, that equation [16] is generally applicable.

Figure 6 shows the functions $\mathrm{g}_{\mathrm{I}}$ and $\mathrm{g}_{\mathrm{A}}$ for different values of $\mathrm{r}\left(L_{S} / L\right)$ for the particular cases of under-deck cable-stayed bridges with one strut $(n=1)$ and with multiple struts $(n=\infty)$. On the basis of this figure, we can draw two important conclusions:

- The functions $g_{I}$ and $g_{A}$ take lower values for multiple strut systems, and therefore the relative rigidity $(\chi)$ is smaller and the efficiency of the cable-staying system $(\xi)$ is larger than for single strut systems, as long as all the other variables remain unchanged. Consequently, under-deck cable-staying systems with multiple struts are more efficient in the presence of live load than systems with a single strut.

- The functions $g_{I}$ and $g_{A}$ depend mostly on the ratio of the length of the midspan strut to the span of the bridge (r) (in other words, the relative eccentricity of the stay cables in the midspan). For values lower than 1/20 of the span, the functions increase asymptotically, so the relative rigidity becomes infinite and the efficiency of the cable-staying system 
Cite this paper as: Ruiz-Teran AM, Aparicio AC, 2007, Parameters governing the response of underdeck cable-stayed bridges, Canadian Journal of Civil Engineering, Vol:34, ISSN:0315-1468, Pages:1016-1024 [doi: 10.1139/L07-016]

becomes zero. Therefore, it is clear that conventional external prestressing does not provide an efficient response to live load. The efficiency of the cable-staying system increases substantially with the increase in eccentricity of the stay cables at midspan.

\subsubsection{Structural response depending on the dimensionless parameter $\chi$. The general case}

If we apply the $\pi$ Theorem (Buckingham 1914), we obtain the form of the implicit function that allows us to calculate the stress changes in the stay cables for a uniform live load $q$ and a point load $Q$ :

$$
F\left[\left(\frac{\Delta \sigma}{E}\right),\left(\frac{Q}{E \cdot L^{2}}\right),\left(\frac{q}{E \cdot L}\right),\left(\frac{A}{L^{2}}\right),\left(\frac{I}{L^{4}}\right),\left(\frac{A_{S C}}{L^{2}}\right),\left(\frac{E_{S C}}{E}\right),(r)\right]=0
$$

It should be noted that, as in the preceding sections, we have disregarded the axial shortening of the struts, since it has little effect on the response. If we had taken it into consideration, it would have introduced two more dimensionless monomials, one of them corresponding to the cross-sectional area of the struts $\left(\mathrm{A}_{\mathrm{S}}\right)$ and the other corresponding to the modulus of deformation of the struts $\left(E_{S}\right)$, with the form:

$$
F\left[\left(\frac{\Delta \sigma}{E}\right),\left(\frac{Q}{E \cdot L^{2}}\right),\left(\frac{q}{E \cdot L}\right),\left(\frac{A}{L^{2}}\right),\left(\frac{I}{L^{4}}\right),\left(\frac{A_{S C}}{L^{2}}\right),\left(\frac{E_{S C}}{E}\right),\left(\frac{A_{S}}{L^{2}}\right),\left(\frac{E_{S}}{E}\right),(r)\right]=0
$$

Therefore, the parameter $\chi$ establishes the relation between the five dimensionless monomials that depend exclusively on the structure, leaving equation [21] reduced to:

$$
F\left[\left(\frac{\Delta \sigma}{E}\right),\left(\frac{Q}{E \cdot L^{2}}\right),\left(\frac{q}{E \cdot L}\right),(\chi),\right]=0
$$

For any response of the structure $(R)$, we can define a dimensionless monomial $\left(R^{*}\right)$ and 
Cite this paper as: Ruiz-Teran AM, Aparicio AC, 2007, Parameters governing the response of underdeck cable-stayed bridges, Canadian Journal of Civil Engineering, Vol:34, ISSN:0315-1468, Pages:1016-1024 [doi: 10.1139/L07-016]

obtain an implicit function, very similar to equation [23], which governs the response of the structure $(R)$ to actions $q$ and $Q$ :

$$
F\left[\left(R^{*}\right),\left(\frac{Q}{E \cdot L^{2}}\right),\left(\frac{q}{E \cdot L}\right),(\chi),\right]=0
$$

\section{Design criteria}

Dealing solely with structural aspects, cable-staying systems with larger eccentricity, i.e. with larger struts, are more efficient. This increase in the efficiency allows a reduction in the crosssectional area of the stay cables. Nevertheless, there are other aspects that must be taken into account in the design process. From an aesthetic point of view, we believe that the length of the struts should be limited to values of around 1/10 of the span (Figure 7), although it should be considered a specific limit for this parameter in each particular case.

The limit state that conditions the design of the stay cables turns out to be the fatigue limit state. The evaluation of this limit state depends on the anchorage technology used and involves the concurrent determination of the two conditions:

- If conventional external prestressing anchorages are used: a) the maximum tension in cable stays less than or equal to the value corresponding to $65 \%$ of the ultimate tensile strength; b) the stress changes in the stay cables due to frequent live load less than or equal to $80 \mathrm{MPa}$.

- If stay cable anchorages are used: a) the maximum stress in stay cables less than or equal to the value corresponding to $45 \%$ of the load of the ultimate tensile strength; b) the stress changes in the stay cables due to frequent live load less than $200 \mathrm{MPa}$.

Firstly, it is necessary to consider that the stress changes in the stay cables due to frequent live 
Cite this paper as: Ruiz-Teran AM, Aparicio AC, 2007, Parameters governing the response of underdeck cable-stayed bridges, Canadian Journal of Civil Engineering, Vol:34, ISSN:0315-1468, Pages:1016-1024 [doi: 10.1139/L07-016]

load must be calculated taking into consideration all the actions that produce frequent stress changes. For example, when the action of the wind produces significant stress changes, it is necessary to take it into consideration in addition to the traffic live load. Furthermore, when the rotation of the stay cable anchorages produces significant stress changes, it is necessary to take it into consideration as well as the stress changes due to elongation of the stay cables.

If the under-deck cable-staying system provides a highly efficient response to live load, the most restrictive condition is that relating to stress changes (condition b). Wherever possible, external prestressing anchorages will be used, since they are more economical.

The larger efficiency of the under-deck cable-stayed system, the greater the reduction of the bending moments in the deck, and the larger the reduction in the depth of the deck, in comparison with bridges without stay cables. The depth of the deck will be dimensioned so that it satisfies the ultimate limit state of normal tensions and even the service limit state of vibrations.

\section{Conclusions}

(1) Certain cable-stayed bridges that have been built define two new types of unconventional cable-stayed bridges. One of those types is the under-deck cable-stayed bridge.

(2) In an under-deck cable-stayed bridge there are two response mechanisms: (1) the axial response (tension of the stay cables and compression of the deck and the struts) and (2) the flexural response (bending of the deck) (Figure 3). If the axial response is reinforced and therefore the flexural response is reduced, much slimmer structures can be built.

(3) The axial response (tension of the stay cables and compression of the struts and the deck) in the permanent state is reinforced by increasing the "span subdivision". The larger the number of intermediate struts, the greater the span subdivision, and the smaller the 
Cite this paper as: Ruiz-Teran AM, Aparicio AC, 2007, Parameters governing the response of underdeck cable-stayed bridges, Canadian Journal of Civil Engineering, Vol:34, ISSN:0315-1468, Pages:1016-1024 [doi: 10.1139/L07-016]

bending moments in the deck under permanent state, on the condition that the stay cables are prestressed to compensate $100 \%$ of the permanent load (dead load and superimposed dead load).

(4) The axial response (tension of the stay cables and compression of the struts and the deck) to live load is reinforced by increasing the "efficiency of the cable-staying system" $(\xi)$. The efficiency of the under-deck cable-staying system is inversely proportional to a parameter that we call "relative rigidity of the deck to the under-deck cable-staying system" $(\chi)$. This is the parameter that governs the response to live load. The cablestaying system is made more efficient by reducing the parameter $\chi$, in other words, by reducing the flexural rigidity of the deck, increasing the tensile rigidity of the stay cables, increasing the span, increasing the length of the struts, increasing the number of struts, and making use of cross-sections with smaller radii of gyration. Consequently, considering the efficiency of the cable-staying system, and not only the construction advantages (Menn and Gauvreau 1990), slab cross-sections are more appropriate than box cross-sections for these types of bridges.

(5) With lengths of the struts at midspan of around 1/10 of the span, it is possible to obtain layouts that are both efficient from a structural point of view and satisfactory from an aesthetic point of view.

(6) The limit state that conditions the design of the stay cables turns out to be the fatigue limit state. This state must be evaluated on the basis of the anchorage technology used.

(7) The depth of the deck must be dimensioned so as to satisfy both the ultimate limit state of normal tensions (bending and compression) and the service limit state of vibrations. However, the study of the dynamic response does not allow a compact analytical 
Cite this paper as: Ruiz-Teran AM, Aparicio AC, 2007, Parameters governing the response of underdeck cable-stayed bridges, Canadian Journal of Civil Engineering, Vol:34, ISSN:0315-1468, Pages:1016-1024 [doi: 10.1139/L07-016]

treatment such as the one made for the static response to permanent load and vertical live load.

\section{Acknowledgments}

The authors would like to express their sincere gratitude to Nicolas Janberg (www.structurae.de, Germany) and Javier Manterola (Carlos Fernández Casado S.L., Spain) that have provided us with both the pictures included in this paper and their publishing permission. The authors would also like to express their gratitude to the Spanish Ministry of Education for the post-doctoral fellowship received by the first author. 
Cite this paper as: Ruiz-Teran AM, Aparicio AC, 2007, Parameters governing the response of underdeck cable-stayed bridges, Canadian Journal of Civil Engineering, Vol:34, ISSN:0315-1468, Pages:1016-1024 [doi: 10.1139/L07-016]

\section{References}

Aravinthan, T., Witchukreangkrai, E., and Mutsuyoshi, H. 2005. Flexural behaviour of twospan continuous prestressed concrete girders with highly eccentric external tendons. ACI Structural Journal, 102(3): 402-411.

Buckingham, E. 1914. On physically similar systems; illustrations of the use of dimensional equations. Phys. Rev., 4: 345-376.

Fürst, A., and Marti, P. 1999. Experimental tests of precast beams with prestressing below the deck (Versuche an trägern mit unterspannung aus vorfabrizierten, vorgespannten betonzuggliedern). IBK. ETH. Zürich, Switzerland (in German).

Laffanchi, M., and Marti, P. 1999. Conception of curved bridges (Zur konzeption gekrümmter brücken). IBK. ETH. Zürich, Switzerland (in German).

Lemaitre, C., and Kobler, M. 2005. Course on sketching and designing civil engineering (Entwerfen und konstruieren von ingenieurbauten). University of Stuttgart. (in German)

Leonhardt, F. 1982. Bridges (Ponts, Puentes). Presses polytechniques romandes, Lausanne, Switzerland. (in French and Spanish).

Lluch, A., Loran, G., and Plaja, A. 2001.Transverse axis of Catalonia. Bridges and tunnels: dialogue between technical and landscape (L'eix Transversal de Catalunya. Ponts i túnels: diàleg de la tècnica amb el paisatge). Generalitat de Catalunya. Departament de Política Territorial i Obres Públiques, Catalonia (in Catalan and Spanish).

Menn, C., and Gauvreau, P. 1990. Externally prestressed concrete slab bridges: model test results. ACI SP, 120: 289-304 
Cite this paper as: Ruiz-Teran AM, Aparicio AC, 2007, Parameters governing the response of underdeck cable-stayed bridges, Canadian Journal of Civil Engineering, Vol:34, ISSN:0315-1468, Pages:1016-1024 [doi: 10.1139/L07-016]

Muttoni, A. 2002. Bridges with under-deck cable staying systems (Brücken mit vorgespannter Stahlunterspannung). Stahlbau, pp. 592-597

Ploch, J. 2004. Definition of the concept of security in prestressing (Zur definition und zum sicherheitskonzept der vorspannung). Institut für Leichtbau Entwerfen und Konstruieren, ILEK, University of Stuttgart, Germany (in German).

Ruiz-Teran, A.M. 2005. Unconventional cable-stayed bridges. Structural behaviour and design criteria (Puentes con atirantamiento no convencional. Comportamiento structural y criterios de diseño). Doctoral Thesis. Supervised by A.C. Aparicio. University of Cantabria, Spain (in Spanish).

Ruiz-Teran, A.M., and Aparicio, A.C. 2006. Two new types of bridges: under-deck cablestayed bridges and combined cable-stayed bridges. The state of the art. Canadian Journal of Civil Engineering

Saitoh, M. 1998. Role of string: Aesthetics and technology of tension structures. IABSE Symposium. Long-span and high-rise structures. Kobe, Japan.

Umezu, K., Fujita, M., and Yamazaki, J. 1998. Study of a new structural type for prestressed concrete bridges. IABSE Symposium. Long-span and high-rise structures. Kobe, Japan.

Virlogeux, M., Bouchon, E., Lefevre, J., Resplendino, J., Crocherie, A., Ageron, C., Bourjot, A., Clement, M., Million, P., Gudefin, C., and Valence, M. 1994. A Prestressed concrete slab supported from below: The Truc de la Fare Bridge. La Technique Francaise du Beton Precontraint. XII Congres de la FIP Federation Internationale de la Precontrainte. Association Française Pour la Construction, Washington. 
Cite this paper as: Ruiz-Teran AM, Aparicio AC, 2007, Parameters governing the response of underdeck cable-stayed bridges, Canadian Journal of Civil Engineering, Vol:34, ISSN:0315-1468, Pages:1016-1024 [doi: 10.1139/L07-016]

\section{List of symbols}

$\mathrm{f}_{\mathrm{Q}}$ : factor taking into account the fact that there is only one point load $\mathrm{Q}$ on the bridge.

g1: dead load (self weight of the structural elements)

g2: superimposed dead load (self weight of the non structural elements)

$\mathrm{g}_{\mathrm{A}}$ : geometric function of the term $\chi_{\mathrm{I}} \chi_{\mathrm{A}}$

$\mathrm{g}_{\mathrm{I}}$ : geometric function of the term $\chi_{\mathrm{I}}$

$\mathrm{n}$ : number of struts

q: uniform live load

$\mathrm{r}$ : relative length of the midspan strut in respect of the span of the bridge or relative eccentricity of under-deck cable-stayed system at midspan section

s: separation between struts

A: cross-sectional area of the deck

As: cross-sectional area of the struts

$\mathrm{A}_{\mathrm{SC}}$ : cross-sectional area of the stay cables

E: modulus of deformation of the deck

$\mathrm{E}_{\mathrm{CS}}$ : modulus of elasticity of the stay cables

$E_{S}$ : modulus of elasticity of the struts

I: moment of inertia of the deck 
Cite this paper as: Ruiz-Teran AM, Aparicio AC, 2007, Parameters governing the response of underdeck cable-stayed bridges, Canadian Journal of Civil Engineering, Vol:34, ISSN:0315-1468, Pages:1016-1024 [doi: 10.1139/L07-016]

L: span Length

$\mathrm{L}_{\mathrm{S}}$ : strut Length

Q: point live load

$\mathrm{R}$ : response

$\mathrm{R}^{*}$ : dimensionless monomial of response $\mathrm{R}$

Ro: vertical force in the strut in permanent state

$\alpha$ : angle formed by the stay cables with the deck

$\chi$ : relative rigidity of the deck to the under-deck cable-staying system

$\chi_{\mathrm{A}}$ : factor influencing the relative rigidity of the deck in respect of the cable-staying system and taking into account the axial shortening of the deck

$\chi_{\mathrm{I}}$ : relative rigidity of the deck in respect of the cable-staying system disregarding the axial shortening of the deck

$\rho$ : degree of compensation of the permanent load

$\sigma_{0}$ : prestressing tension of the stay cables

$\xi:$ efficiency of the cable-staying system under live load

$\Delta \sigma_{\mathrm{SC}}:$ stress changes in stay cables due to live load 
Cite this paper as: Ruiz-Teran AM, Aparicio AC, 2007, Parameters governing the response of underdeck cable-stayed bridges, Canadian Journal of Civil Engineering, Vol:34, ISSN:0315-1468, Pages:1016-1024 [doi: 10.1139/L07-016]

\section{List of Figures}

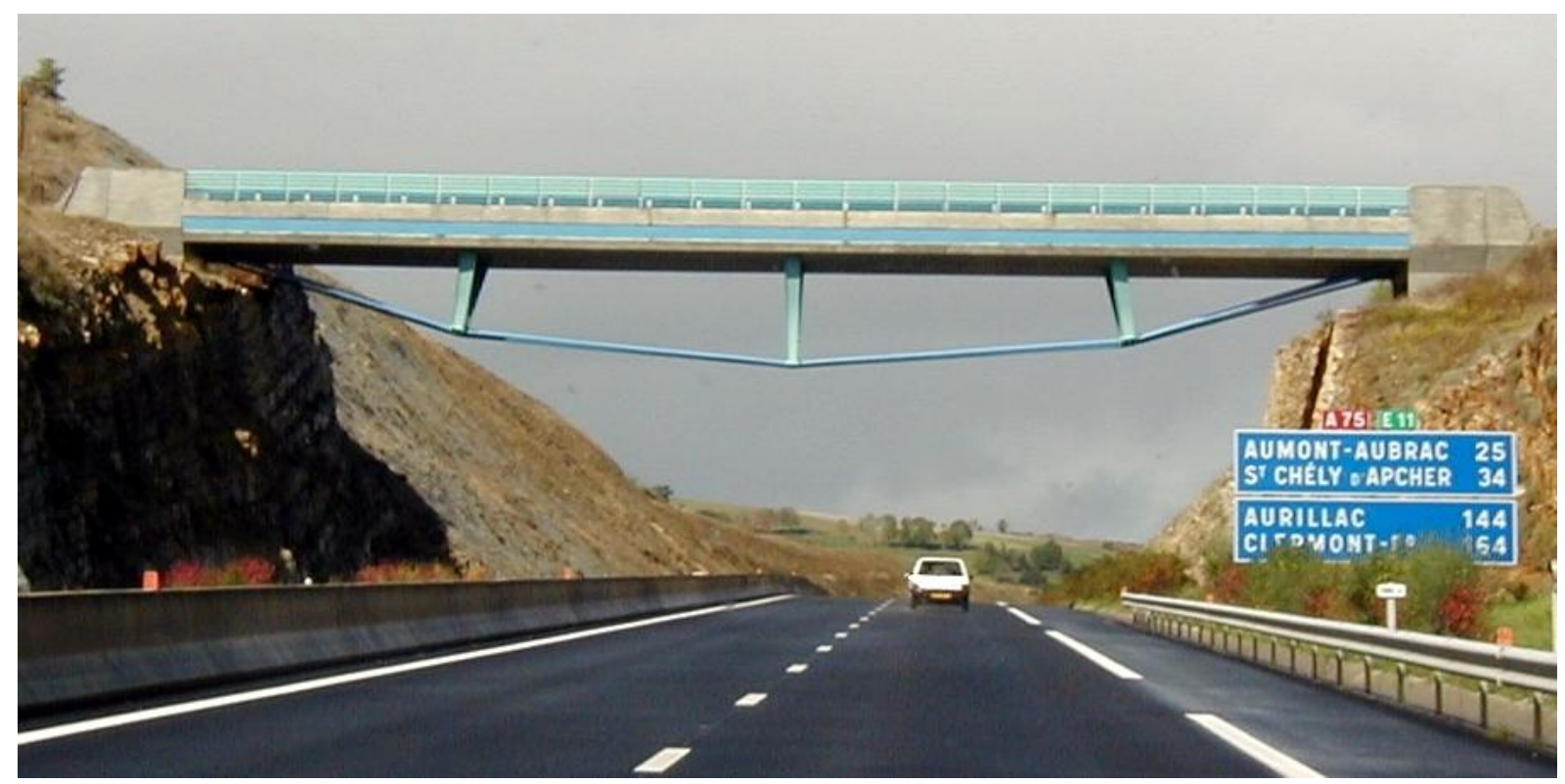

Figure 1: Truc de la Fare overpass (courtesy of Nicolas Janberg, www.structurae.de) 
Cite this paper as: Ruiz-Teran AM, Aparicio AC, 2007, Parameters governing the response of underdeck cable-stayed bridges, Canadian Journal of Civil Engineering, Vol:34, ISSN:0315-1468, Pages:1016-1024 [doi: 10.1139/L07-016]

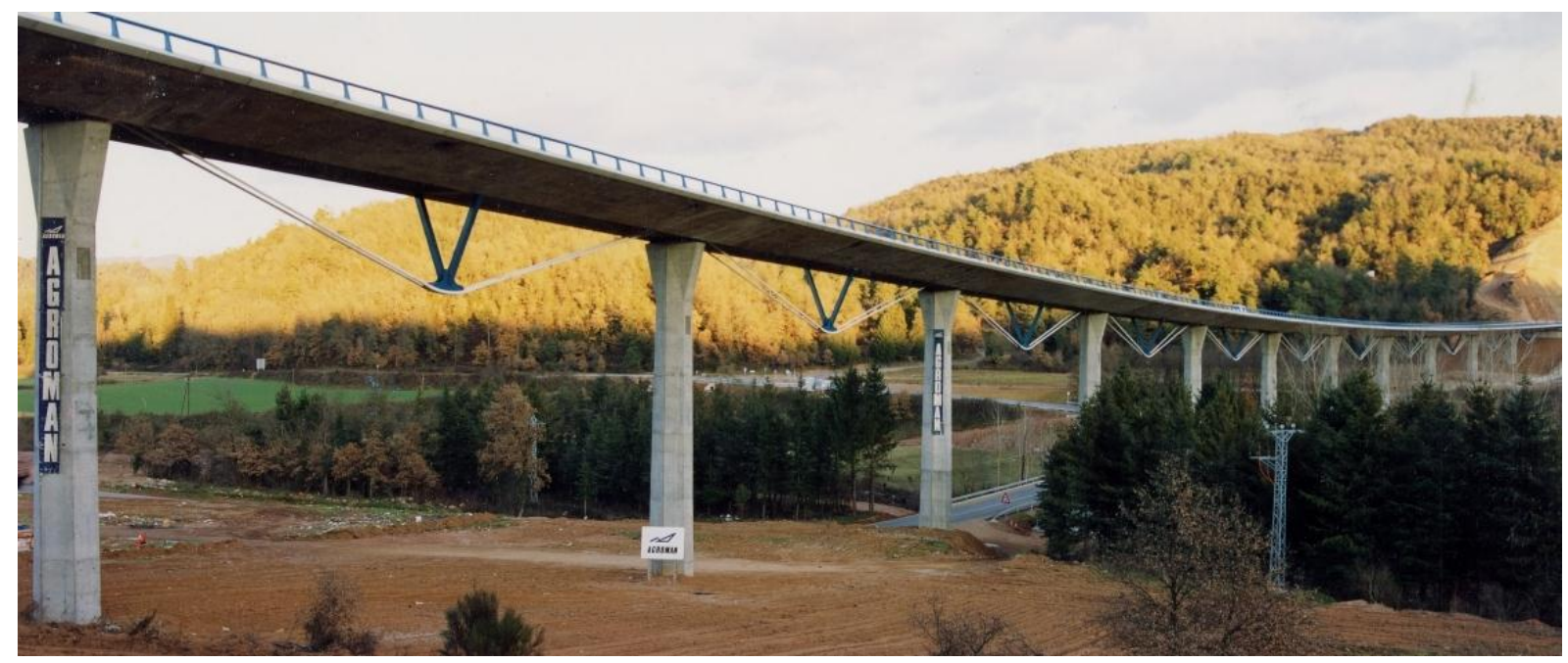

Figure 2: Osormort viaduct (courtesy of Javier Manterola, Carlos Fernández Casado S.L.) 
Cite this paper as: Ruiz-Teran AM, Aparicio AC, 2007, Parameters governing the response of underdeck cable-stayed bridges, Canadian Journal of Civil Engineering, Vol:34, ISSN:0315-1468, Pages:1016-1024 [doi: 10.1139/L07-016]

(a)

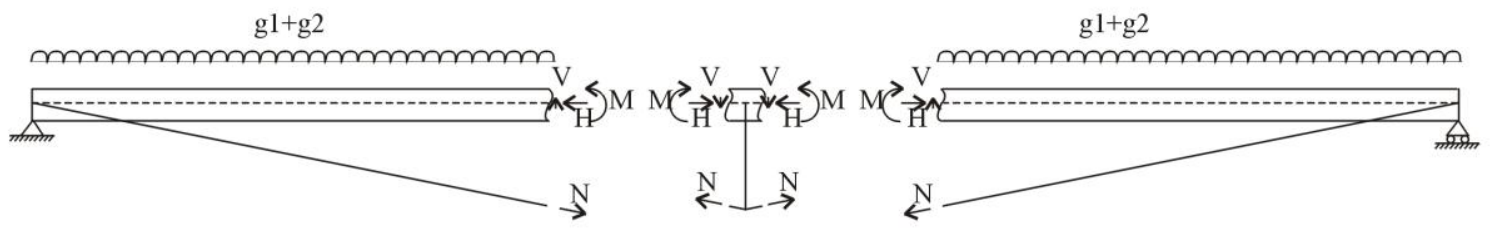

(b)

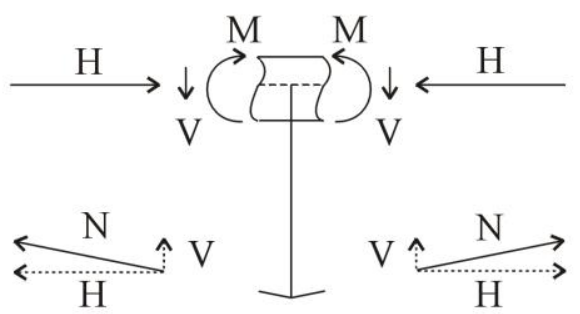

Moment resisted by the deck $=\mathrm{M} \quad$ [Flexural Response] Moment resisted by the stay cables $=\mathrm{H} \cdot$ Strut Length [Axial Response]

Isostatic moment at midspan $=$ Moment resisted by the deck + Moment resisted by the stay cables

Figure 3: (a) Response mechanisms of an UCSB under live load, (b) amplification 
Cite this paper as: Ruiz-Teran AM, Aparicio AC, 2007, Parameters governing the response of underdeck cable-stayed bridges, Canadian Journal of Civil Engineering, Vol:34, ISSN:0315-1468, Pages:1016-1024 [doi: 10.1139/L07-016]

\begin{tabular}{|c|c|c|c|c|c|c|}
\hline & $\xi$ & $\mathrm{M}_{\text {MIDDLE SPAN }}$ & $\mathrm{M}_{\mathrm{SUPPORTS}}$ & $\Delta \sigma_{\text {STAY CABLES }}$ & $\mathrm{d}_{\mathrm{MIDDLE}} \mathrm{SPAN}$ & $\Delta \mathrm{N}_{\mathrm{DECK}}$ \\
\hline & $\frac{5}{4} \cdot \frac{1}{1+12 x}$ & $\frac{q \cdot L^{2}}{8} \cdot(1-\xi)$ & - & $\frac{q \cdot L}{4 \cdot \sin (\alpha) \cdot A_{S C}} \cdot \xi$ & $\frac{5 \cdot q \cdot L^{4}}{384 \cdot E \cdot I} \cdot\left(1-\frac{4}{5} \xi\right)$ & $\frac{q \cdot L}{4 \cdot \operatorname{tg}(\alpha)} \cdot \xi$ \\
\hline$\stackrel{\downarrow^{\natural}}{\perp}$ & $\frac{1}{1+12 \chi}$ & $\frac{Q \cdot L}{4} \cdot(1-\xi)$ & - & $\frac{Q}{2 \cdot \sin (\alpha) \cdot A_{S C}} \cdot \xi$ & $\frac{Q \cdot L^{3}}{48 \cdot E \cdot I} \cdot(1-\xi)$ & $\frac{Q}{2 \cdot \operatorname{tg}(\alpha)} \cdot \xi$ \\
\hline$\left(\begin{array}{ll}M & M^{2} \\
\end{array}\right.$ & $\frac{3}{2} \cdot \frac{1}{1+12 x}$ & $M \cdot(1-\xi)$ & $M$ & $\frac{2 \cdot M}{L \cdot \sin (\alpha) \cdot A_{s c}} \cdot \xi$ & $\frac{M \cdot L^{2}}{8 \cdot E \cdot I} \cdot\left(1-\frac{2}{3} \xi\right)$ & $\frac{2 \cdot M}{L \cdot \operatorname{tg}(\alpha)} \cdot \xi$ \\
\hline ב. & $\frac{1}{1+48 x}$ & $\frac{q \cdot L^{2}}{24} \cdot\left(1-\frac{3}{2} \cdot \xi\right)$ & $-\frac{q \cdot L^{2}}{12} \cdot\left(1-\frac{3}{4} \cdot \xi\right)$ & $\frac{q \cdot L}{4 \cdot \sin (\alpha) \cdot A_{s C}} \cdot \xi$ & $\frac{q \cdot L^{+}}{384 \cdot E \cdot I} \cdot(1-\zeta)$ & $\frac{q \cdot L}{4 \cdot \operatorname{tg}(\alpha)} \cdot \xi$ \\
\hline$\stackrel{\downarrow^{Q}}{=}=$ & $\frac{1}{1+48 x}$ & $\frac{Q \cdot L}{8} \cdot(1-\xi)$ & $-\frac{Q \cdot L}{8} \cdot(1-\xi)$ & $\frac{Q}{2 \cdot \sin (\alpha) \cdot A_{s c}} \cdot \xi$ & $\frac{Q \cdot L^{3}}{192 \cdot E \cdot I} \cdot(1-\xi)$ & $\frac{Q}{2 \cdot \operatorname{tg}(\alpha)} \cdot \xi$ \\
\hline
\end{tabular}

Figure 4: Response under live load of an UCSB with one midspan strut. 
Cite this paper as: Ruiz-Teran AM, Aparicio AC, 2007, Parameters governing the response of underdeck cable-stayed bridges, Canadian Journal of Civil Engineering, Vol:34, ISSN:0315-1468, Pages:1016-1024 [doi: 10.1139/L07-016]

\begin{tabular}{|c|c|c|c|c|c|}
\hline & $\xi$ & $\mathrm{M}_{\text {MIDDLE SPAN }}$ & $\Delta \sigma_{\text {STAY CABLES }}$ & $\mathrm{d}_{\text {MIDDLE SPAN }}$ & $\Delta \mathrm{N}_{\mathrm{DECK}}$ \\
\hline sq & $\frac{1}{1+12 \cdot x}$ & $\frac{q \cdot L^{2}}{8} \cdot(1-\xi)$ & $\frac{q \cdot L}{8 \cdot r \cdot A_{s c}} \cdot \xi$ & $\frac{5 \cdot q \cdot L^{4}}{384 \cdot E \cdot I} \cdot(1-\xi)$ & $\frac{q \cdot L}{8 \cdot r} \cdot \xi$ \\
\hline 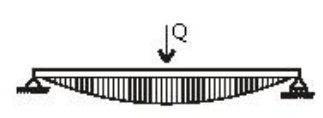 & $\frac{25}{32} \cdot \frac{1}{1+12 \cdot \chi}$ & $\frac{Q \cdot L}{4} \cdot(1-\xi)$ & $\frac{Q}{4 \cdot r \cdot A_{S C}} \cdot \xi$ & $\frac{Q \cdot L^{3}}{48 \cdot E \cdot I} \cdot\left(1-\frac{5}{4} \cdot \xi\right)$ & $\frac{Q}{4 \cdot r} \cdot \xi$ \\
\hline
\end{tabular}

Figure 5: Response under live load of an UCSB with multiple struts. 
Cite this paper as: Ruiz-Teran AM, Aparicio AC, 2007, Parameters governing the response of underdeck cable-stayed bridges, Canadian Journal of Civil Engineering, Vol:34, ISSN:0315-1468, Pages:1016-1024 [doi: 10.1139/L07-016]

(a)

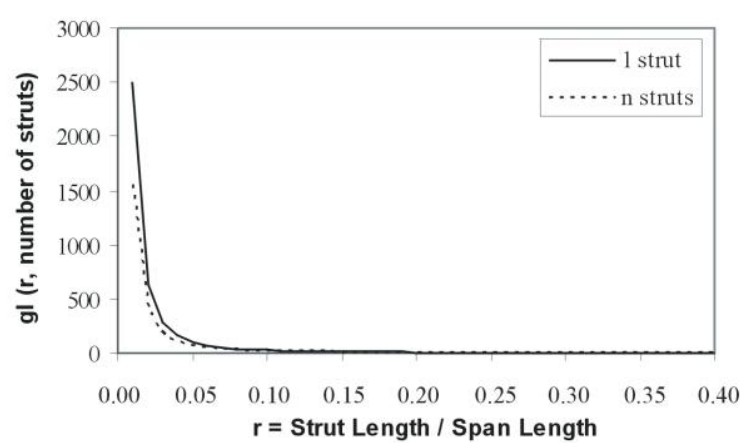

(b)

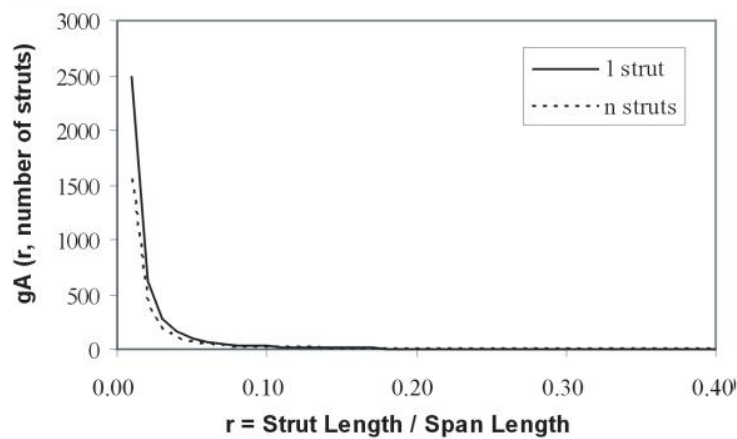

(c)

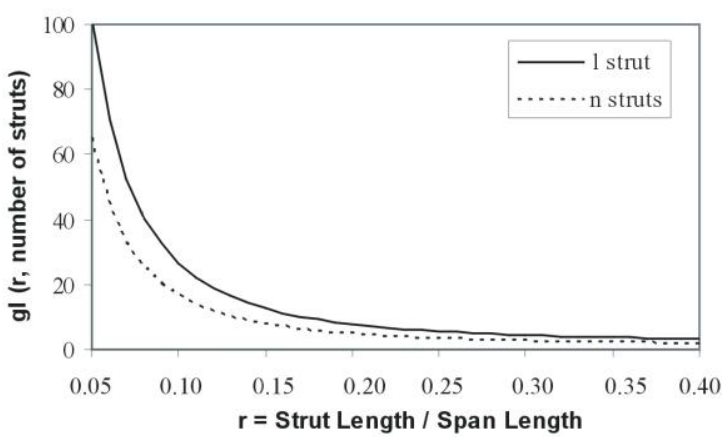

(d)

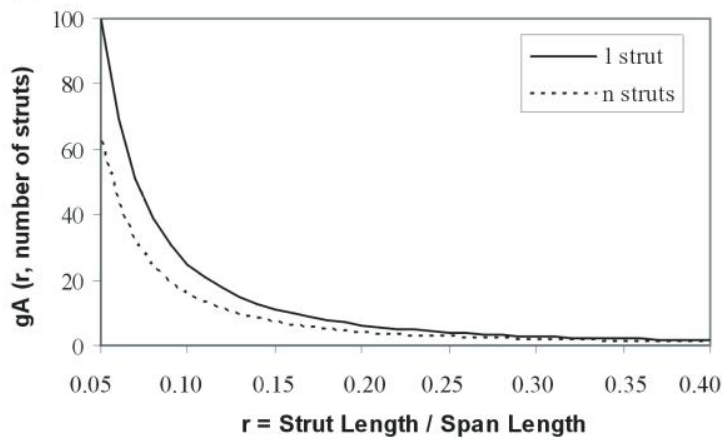

Figure 6: Functions gI(r) and gA(r) in an UCSB: (a) gI(r); (b) gA(r); (c), (d) amplifications 
Cite this paper as: Ruiz-Teran AM, Aparicio AC, 2007, Parameters governing the response of underdeck cable-stayed bridges, Canadian Journal of Civil Engineering, Vol:34, ISSN:0315-1468, Pages:1016-1024 [doi: 10.1139/L07-016]

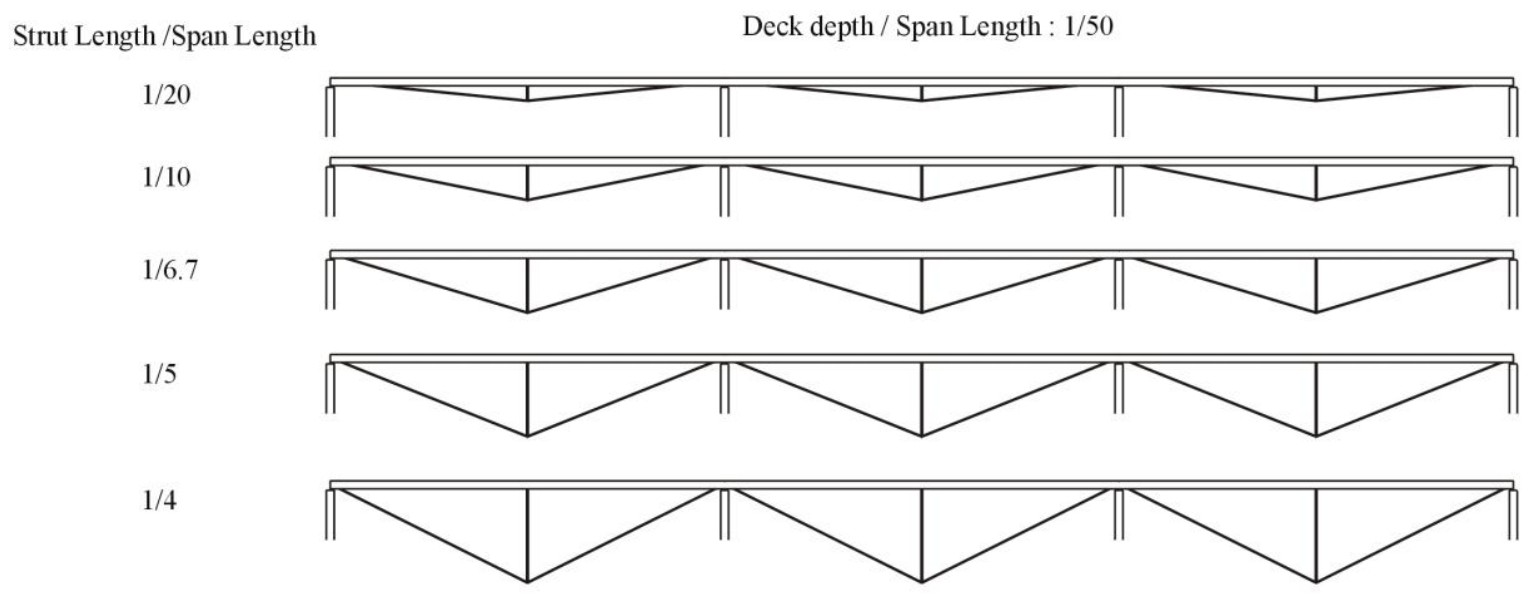

Figure 7: Appearance of UCSBs for different relative lengths of struts in respect of the span 